\title{
Associations between Childhood Disadvantage and Adult Body Mass Index Trajectories: A Follow-Up Study among Midlife Finnish Municipal Employees
}

\author{
Jatta Salmela ${ }^{a}$ Elina Mauramo ${ }^{a} \quad$ Tea Lallukka a, b Ossi Rahkonen ${ }^{a}$ \\ Noora Kanerva ${ }^{a}$ \\ aUniversity of Helsinki, Department of Public Health, Helsinki, Finland; ${ }^{b}$ Finnish Institute of \\ Occupational Health, Helsinki, Finland
}

\section{Keywords}

Body mass index · Trajectory · Childhood adversities · Education · Weight gain

\begin{abstract}
Objective: Childhood disadvantage is associated with a higher risk of adult obesity, but little is known about its associations with body mass index (BMI) trajectories during adulthood. This study aimed first to identify adulthood BMI trajectories, and second to investigate how childhood disadvantage is associated with trajectory group membership. Methods: Data from the Helsinki Health Study, a longitudinal cohort study of initially 40- to 60-year-old employees of the City of Helsinki in Finland, were used. The baseline survey was conducted in 2000-2002, and similar follow-up surveys in 2007, 2012, and 2017. Based on self-reported BMI, participants' ( $n=5,266 ; 83 \%$ women) BMI trajectories, including their retrospectively reported BMI at the age of 25 years, were examined. Data on childhood disadvantage, including parental education and 7 types of childhood adversity (their own serious illness; parental divorce, death, mental disorder, or alcohol problems; economic difficulties at home; and peer group bullying) before the age of 16 years, were obtained from the baseline survey. Group-based trajectory modeling was used to identify BMI trajectories, and multinomial logistic regression to analyze the odds for trajectory group membership for the disadvantage variables. Results: Four ascending BMI trajectories in women and men were found: persistent normal weight (trajectory 1 ; women $35 \%$ and men 25\%), normal weight to overweight (trajectory 2; women $41 \%$ and men $48 \%$ ), normal weight to class I obesity (trajectory 3; women $19 \%$ and men 23\%) and overweight to class II obesity (trajectory 4; women $5 \%$ and men 4\%). Compared to trajectory 1 , women with multiple adversities and repetitive peer bullying in childhood had greater odds of belonging to trajectories 3 and 4, whereas men with parental alcohol problems had
\end{abstract}


greater odds of belonging to trajectory 4. For women and men, a low level of parental education was associated with a higher-level BMI trajectory. Conclusions: Low parental education for both genders, multiple adversities and repetitive peer bullying in childhood among women, and parental alcohol problems among men increased the odds of developing obesity during adulthood. Further studies are needed to clarify how gender differences modify the effects of childhood disadvantage on adult BMI trajectories.

(C) 2019 The Author(s)

Published by S. Karger AG, Basel

\section{Introduction}

Obesity is a worldwide health problem which has increased during past decades in an accelerated way $[1,2]$. Childhood socioeconomic disadvantage, such as a low level of parental education, is associated with weight gain and obesity in adulthood [3-5]. Several childhood adversities, e.g., household economic difficulties and maltreatment, are also associated with adulthood obesity and general poor health [6-8]. These disadvantages may promote the longterm development of obesity via several pathways. For instance, multiple physiological, psychosocial, and environmental factors as well as an unhealthy lifestyle may promote weight gain from early to later adulthood [9-11]. The associations between childhood disadvantage and adulthood obesity seem to be stronger in women [12] and it appears that the childhood adversities associated with adulthood obesity differ when comparing women and men [7]. However, we still lack evidence on which of the adversities are the strongest risk factors for the developmental path of obesity and how these differ between genders.

Most previous studies have been limited to investigating associations between childhood disadvantage and adulthood obesity, without considering the heterogeneity of the study population in the developmental path of weight change over time (e.g., $[3,4,11])$. Trajectory modeling, such as group-based trajectory modeling [13], is becoming a more popular approach in obesity research as it enables capturing distinct subpopulations with different time-varying curves of longitudinal weight change. A few studies have examined how childhood socioeconomic disadvantage is associated with the body mass index (BMI) trajectory in midlife and later adulthood, showing an increased risk of weight gain for those in a worse socioeconomic situation in childhood, especially women [14, 15]. In addition, in studies on childhood adversity, the BMI trajectory has been limited to early adulthood only [16, 17]. Thus, more studies are needed to investigate various types of childhood disadvantage and their effects on long-term weight changes in later adulthood. The aim of this study was to identify adult BMI trajectories among midlife municipal employees of the City of Helsinki, Finland, and to investigate how childhood disadvantage, including parental education and different types of childhood adversity, is associated with these trajectories.

\section{Material and Methods}

\section{Study Design and Participants}

The prospective data were derived from the Helsinki Health Study (HHS), a large cohort study on social and work-related determinants of health including baseline and 3 follow-up surveys. All the employees of the City of Helsinki, Finland, aged 40, 45, 50, 55, and 60 years $(n=13,346)$ were invited to participate in the baseline survey (2000-2002), resulting in a response rate of $67 \%(n=8,960)$ [18]. Of these participants, $80 \%$ were women, which represents the gender distribution among the employees of the City of Helsinki and the municipal sector in Finland in general. Follow-up surveys for those who participated the baseline survey 
Salmela et al.: Childhood Disadvantage and Adult BMI Trajectories

were conducted in 2007,2012, and 2017, and corresponding response rates were 83,79 , and $82 \%$, respectively. Respondents with missing BMI data in any phase $(n=3,682)$ and those who were pregnant during the baseline survey $(n=12)$ were excluded. The final data for analysis involved 4,348 women and 918 men.

\section{Variables}

Outcome: Body Mass Index (BMI)

In each phase, BMI was calculated based on self-reported weight and height. When appointing the trajectory groups, normal weight was defined as BMI 18.5-24.9, overweight as BMI 25.0-29.9, class I obesity as BMI 30.0-34.9, and class II obesity as BMI 35.0-39.9. Additionally, at the baseline survey, participants reported their weight at the time they were 25 years old (excluding pregnancy). Based on this retrospective information, BMI in young adulthood, i.e., at the age of 25 years, was calculated and included to have a longer follow-up of the course of BMI and development of weight gain over time.

Exposure: Parental Education and Childhood Adversity

Information on parental education and childhood adversities was derived from the baseline survey. Data on the mother's and father's education were obtained, and the higher of the two was chosen. Matriculation or college examination or higher was classified as higher education, and less than that as low education. Concerning childhood adversity, the participants were asked whether they had experienced any of the following 7 adversities before the age of 16 years: their own serious or long-term illness; parental divorce, death, mental disorder, or alcohol problems; economic difficulties at home; and repetitive peer group bullying. When calculating the score for investigating multiple childhood adversities, each "Yes" answer scored 1 point, i.e., a participant could score $0-7$ points. A total of 0 points was classified as "no adversities," 1-2 points "few adversities," and 3-7 points "several adversities." Participants with missing information on all adversities were excluded (74 women and 14 men).

\section{Statistical Analyses}

Group-based trajectory modeling (GBTM) was used to identify the BMI trajectory groups. GBTM is an application of finite mixture modeling which assumes that a population is composed of a mixture of distinct groups defined by their developmental trajectories [13]. The application utilizes a multinomial modeling strategy and uses maximum likelihood for the estimation of the model parameters [19]. The number of optimal trajectory groups and trajectory shapes were chosen based on the following statistical criteria: Bayesian information criteria (BIC), the average of the posterior probability (APP) for group membership of $>0.7$, and a trajectory group size $>5 \%$ [13].

Trajectories were identified separately for women and men due to possibly different predictors of the developmental patterns of BMI $[7,20]$. In addition, a distinct interpretability of the identified trajectory groups and the existing literature was considered when assessing the best model. Each participant was assigned to the trajectory group for which they had the highest probability of group membership. The APP of group membership was $>0.9$ for women and men, and $7 \%$ of women and men had a posterior probability of group membership $<0.7$. The model fit statistics are shown in online supplementary Table 1 (for all online suppl. material, see www.karger.com/doi/10.1159/000502237) for women and online supplementary Table 2 for men.

Descriptive analyses by childhood disadvantage were performed. Multinomial logistic regression was used to investigate the association between predictors (parental education and childhood adversities) and trajectory group membership. Regression analyses were all 
Salmela et al.: Childhood Disadvantage and Adult BMI Trajectories

Table 1. Characteristics of the study population by childhood disadvantage

\begin{tabular}{|c|c|c|}
\hline Childhood disadvantage $^{a}$ & Women & Men \\
\hline \multicolumn{3}{|l|}{ Parental education } \\
\hline Low & 3,387 (77.9) & $658(71.7)$ \\
\hline High & $924(21.3)$ & $257(28.0)$ \\
\hline \multicolumn{3}{|l|}{ Own serious illness } \\
\hline Yes & $278(6.4)$ & $68(7.4)$ \\
\hline No & $3,655(84.1)$ & $779(84.9)$ \\
\hline \multicolumn{3}{|l|}{ Parental divorce } \\
\hline Yes & 403 (9.3) & $108(11.8)$ \\
\hline No & $3,534(81.3)$ & $741(80.7)$ \\
\hline \multicolumn{3}{|l|}{ Parental death } \\
\hline Yes & $539(12.4)$ & $122(13.3)$ \\
\hline No & $3,434(79.0)$ & $727(79.2)$ \\
\hline \multicolumn{3}{|l|}{ Parental mental disorder } \\
\hline Yes & $235(5.4)$ & $40(4.4)$ \\
\hline No & $3,667(84.3)$ & $794(86.5)$ \\
\hline \multicolumn{3}{|l|}{ Parental alcohol problems } \\
\hline Yes & 790 (18.2) & $177(19.3)$ \\
\hline No & $3,203(73.7)$ & $674(73.4)$ \\
\hline \multicolumn{3}{|c|}{ Economic difficulties at home } \\
\hline Yes & 778 (17.9) & $158(17.2)$ \\
\hline No & $3,216(74.0)$ & $698(76.0)$ \\
\hline \multicolumn{3}{|l|}{ Peer group bullying } \\
\hline Yes & $304(7.0)$ & $78(8.5)$ \\
\hline No & $3,632(83.5)$ & $759(82.7)$ \\
\hline \multicolumn{3}{|l|}{ Childhood adversities } \\
\hline Several (3-7) & $314(7.2)$ & $74(8.1)$ \\
\hline Few $(1-2)$ & $1,732(39.7)$ & $367(40.0)$ \\
\hline None & $2,240(51.4)$ & $463(50.4)$ \\
\hline
\end{tabular}

Values express $n(\%) .{ }^{\text {a }}$ Includes parental education and childhood adversities before the age of 16 years.

adjusted for participants' age at the baseline survey phase (2000-2002). Childhood disadvantage (low parental education and 7 childhood adversities) and multiple childhood adversities (adversity score) were examined as separate entities. From these analyses, the odds ratios (OR) and their 95\% confidence intervals (CI) were reported. As a sensitivity analysis, all regression analyses were redone by excluding those with any missing information for exposure variables ( 611 women and $108 \mathrm{men}$ ). The results of the sensitivity analysis yielded results that were almost identical to the main results. STATA v15 with TRAJ command [19] was used for identifying the trajectory groups, and the rest of the analyses were performed using SPSS v22. $p=0.05$ was the cutoff for significance and indicated that there was a difference between having a type of childhood disadvantage and not having it in a higher trajectory group related to the lowest.

\section{Results}

The majority of participants reported a low level of parental education (women 78\% and men $72 \%$; Table 1). Half of the participants had experienced at least 1 adversity before the age of 16 years (women $49 \%$ and men 50\%). The most common adversities were parental 
Fig. 1. BMI trajectories among women identified by group-based trajectory modeling. Group means and fitted lines with 95\% confidence intervals.

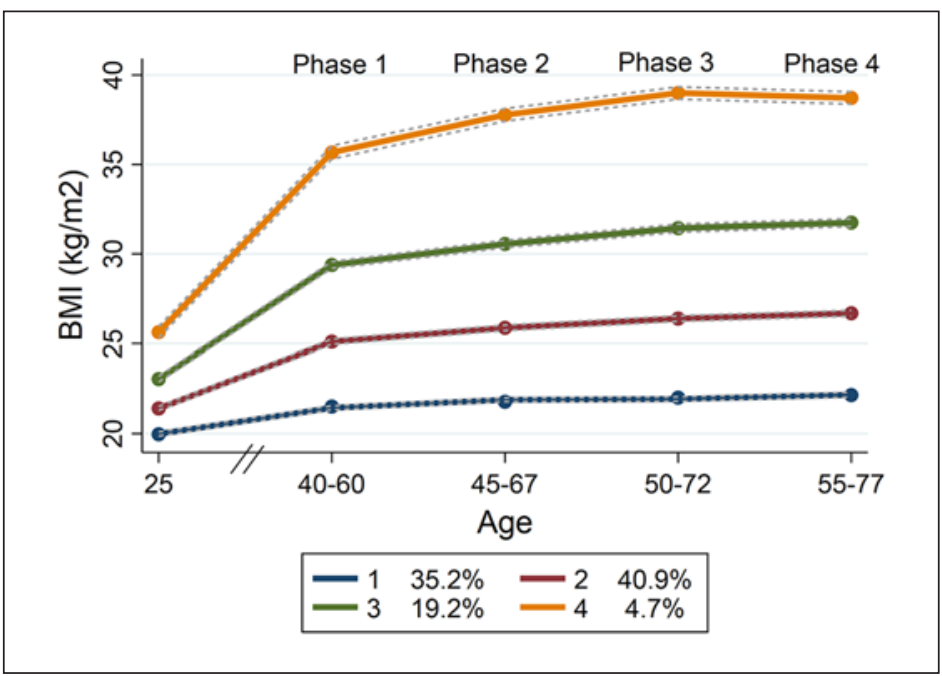

Fig. 2. BMI trajectories among men identified by group-based trajectory modeling. Group means and fitted lines with 95\% confidence intervals.

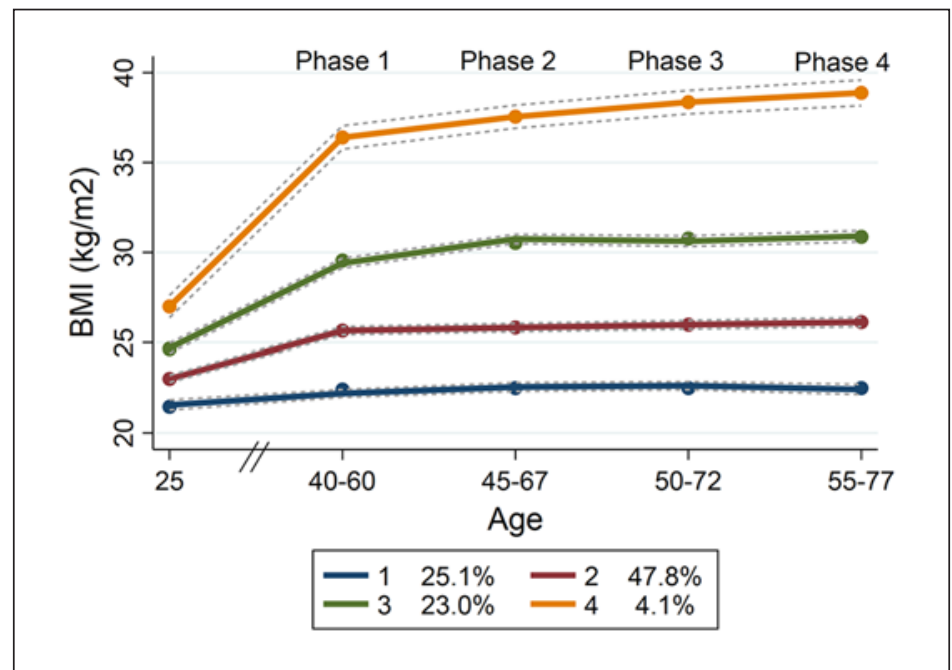

alcohol problems (women 18\% and men 19\%) and economic difficulties at home (women $18 \%$ and men 17\%). The characteristics of the study population by trajectory group are shown in online supplementary Table 3 (women) and Table 4 (men).

Based on the model selection criteria of GBTM, a 4-trajectory solution was chosen for both women (Fig. 1) and men (Fig. 2), yielding the following: persistent normal weight (trajectory 1), normal weight to overweight (trajectory 2), normal weight to class I obesity (trajectory 3), and overweight to class II obesity (trajectory 4). One-third of women and onequarter of men were assigned to trajectory 1 . In both women and men, the probability of belonging to trajectory 2 was the greatest ( $41 \%$ of women and $48 \%$ of men), whereas only $4.7 \%$ of women and $4.1 \%$ of men were assigned to trajectory 4 .

Among women, low parental education and repetitive peer group bullying before the age of 16 years were associated with trajectory groups 3 and 4; Table 2). The odds increased when moving from a lower to a higher BMI trajectory. A subject's own serious or long-term illness in childhood and economic difficulties at home were associated with the higher BMI 
Salmela et al.: Childhood Disadvantage and Adult BMI Trajectories

Table 2. Results from multinomial logistic regression on BMI trajectory group membership among women

\begin{tabular}{llll}
\hline Women $(n=4,384)$ & \multicolumn{2}{l}{ BMI trajectory group } & \\
\cline { 2 - 4 } & trajectory 2 & trajectory 3 & trajectory 4 \\
\hline $\begin{array}{lll}\text { Childhood disadvantage } \\
\quad \text { Low parental education }\end{array}$ & $1.49(1.25-1.78)$ & $1.49(1.19-1.86)$ & $2.58(1.62-4.11)$ \\
$\quad$ Own serious illness & $1.06(0.76-1.49)$ & $1.30(0.88-1.91)$ & $1.77(0.98-3.17)$ \\
$\quad$ Parental divorce & $0.77(0.58-1.03)$ & $1.00(0.71-1.40)$ & $0.82(0.44-1.50)$ \\
$\quad$ Parental death & $1.25(0.98-1.60)$ & $0.77(0.55-1.08)$ & $0.71(0.39-1.27)$ \\
$\quad$ Parental mental disorder & $1.05(0.74-1.50)$ & $0.92(0.60-1.42)$ & $0.85(0.40-1.80)$ \\
$\quad$ Parental alcohol problems & $1.12(0.91-1.39)$ & $1.15(0.89-1.49)$ & $1.05(0.67-1.65)$ \\
$\quad$ Economic difficulties at home & $1.07(0.86-1.34)$ & $1.11(0.85-1.46)$ & $1.29(0.83-1.99)$ \\
$\quad$ Peer group bullying & $1.17(0.82-1.65)$ & $1.73(1.18-2.55)$ & $2.20(1.24-3.92)$ \\
Multiple adversities (no ref.) & & & \\
$\quad$ Several (3-7) & $1.14(0.86-1.51)$ & $1.39(1.00,1.94)$ & $1.69(0.99-2.88)$ \\
Few (1-2) & $1.17(1.01-1.35)$ & $1.23(1.03-1.46)$ & $1.41(1.03-1.91)$ \\
\hline
\end{tabular}

Values are OR (95\% CI). Childhood disadvantage and multiple childhood adversities were investigated as separate entities and adjusted for age. Trajectory group 1 was used as the reference (OR 1.00). ${ }^{\text {a }}$ Includes parental education and childhood adversities before the age of 16 years.

Table 3. Results from multinomial logistic regression on BMI trajectory group membership among men

\begin{tabular}{llll}
\hline Men $(n=918)$ & \multicolumn{2}{l}{ BMI trajectory group } & \\
\cline { 2 - 4 } & trajectory 2 & trajectory 3 & trajectory 4 \\
\hline Childhood disadvantage $^{\text {a }}$ (ref.) & & & \\
$\quad$ Low parental education & $1.48(1.03-2.15)$ & $2.04(1.29-3.22)$ & $1.68(0.71-3.96)$ \\
Own serious illness & $0.74(0.38-1.45)$ & $0.88(0.40-1.91)$ & $1.59(0.48-5.24)$ \\
$\quad$ Parental divorce & $0.64(0.36-1.14)$ & $0.75(0.38-1.50)$ & $0.44(0.12-1.68)$ \\
$\quad$ Parental death & $0.95(0.54-1.65)$ & $1.26(0.67-2.38)$ & $1.28(0.44-3.74)$ \\
Parental mental disorder & $0.71(0.31-1.61)$ & $0.74(0.27-2.00)$ & $0.40(0.05-3.38)$ \\
Parental alcohol problems & $0.91(0.56-1.49)$ & $0.91(0.51-1.64)$ & $2.50(1.02-6.10)$ \\
$\quad$ Economic difficulties at home & $1.17(0.70-1.95)$ & $0.70(0.38-1.33)$ & $1.04(0.38-2.88)$ \\
$\quad$ Peer bullying & $0.74(0.39-1.41)$ & $1.58(0.80-3.14)$ & $0.85(0.22-3.22)$ \\
Adversities (no ref.) & & & \\
Several (3-7) & $0.71(0.40-1.26)$ & $0.60(0.29-1.24)$ & $1.06(0.28-3.98)$ \\
Few (1-2) & $0.81(0.58-1.14)$ & $1.06(0.72-1.57)$ & $1.67(0.80-3.50)$ \\
\hline
\end{tabular}

Values are OR (95\% CI). Childhood disadvantage and multiple childhood adversities were investigated as separate entities and adjusted for age. Trajectory group 1 was used as a reference group (OR 1.00). ${ }^{\text {a Includes }}$ parental education and childhood adversities before the age of 16 years.

trajectory groups (see online suppl. Table 5), but not statistically significantly when examined together with other adversities (Table 2). Having at least 1, but particularly having several childhood adversities (compared to no adversities) increased the odds of belonging to a higher BMI trajectory group.

For men, low parental education was associated with the higher BMI trajectories (Table 3). Parental alcohol problems were associated with trajectory group 4 (OR 2.50; 95\% CI 1.02-6.10), but not with the other trajectories. Multiple adversities in childhood did not increase the odds of belonging to a higher BMI trajectory group. 
Salmela et al.: Childhood Disadvantage and Adult BMI Trajectories

\section{Discussion}

We investigated the associations between childhood disadvantage and adult BMI trajectories among Finnish municipal employees and found 4 ascending BMI trajectories for both women and men: persistent normal weight, normal weight to overweight, normal weight to class I obesity, and overweight to class II obesity. Childhood disadvantage included low parental education and 7 types of childhood adversity. Among women, repetitive peer group bullying and multiple adversities in childhood were associated with the highest BMI trajectory groups; among men, parental alcohol problems were associated with the trajectory of overweight to class II obesity. Low parental education increased the odds of belonging to the trajectories of developing overweight or obesity among both women and men.

Few studies have identified the role of childhood disadvantage contributing to BMI trajectory in middle and late adulthood. Our findings add to the existing literature by investigating this separately in women and men. In previous studies by our study group, adult socioeconomic disadvantage was associated with adult obesity, and childhood adversities were associated with poorer work disability trajectories in midlife [21, 22]. In general, a poorer socioeconomic position in childhood has been consistently associated with higher BMI in adulthood [5, 12, 23], and some studies have found it to be associated with higher and ascending BMI trajectories in adulthood $[14,15]$ consistent with our results. The role of socioeconomic inequality in weight gain can be seen already in early childhood and is greater toward adulthood [24]. Also, multiple adversities seem to increase the risk of adult obesity as well as other health outcomes, more than a single adversity does $[25,26]$. Our study supported these previous findings, but only among women.

Some studies have found no gender differences in adult BMI trajectories [27, 28] whereas others have found an increased risk for women to belong to overweight or obese trajectories $[15,29]$. Even though the BMI trajectories in our study were similar for women and men, the associated childhood risk factors differed between genders. Our results showed that several childhood adversities were associated with a higher BMI trajectory group among women but not among men. In general, the associations between childhood adversities and obesity seem to be stronger in women $[7,30]$. Genetic and biological differences may play a role here, as the genetic influence on long-term adult weight gain [31] and also the stress response to childhood disadvantage and psychosocial vulnerability are stronger in women [7, 20]. For instance, girls are especially emotionally vulnerable to bullying about weight [32]; we also found peer group bullying to be associated with the development of obesity among women but not men. In addition, socioeconomic inequality as a factor for weight gain seems to be stronger in women, with educational differences in women's BMI existing already before adulthood [24, 33].

The link of childhood disadvantage to adulthood obesity may be explained by several physiological, psychosocial, and environmental factors, and their complex interplay $[9,10]$. Lifestyle (e.g., smoking), health status (e.g., disordered eating and depression), and social factors (e.g., family support) may act as mediators in the pathway between childhood adversities and adulthood health and weight status [11,30,34]. The accumulation of various risk factors is generally known to affect later health [35], which may partly be explained by later socioeconomic disadvantages and weakened self-regulation in response to chronic stress $[12,36,37]$. Nevertheless, childhood adversities seem to be linked to adult obesity regardless of socioeconomic, psychological, and lifestyle factors, indicating that possible direct mechanisms are involved $[30,38]$. Childhood stressors may have long-term effects on the nervous, endocrine, and immune systems, such as increased inflammation and cortisol levels, which increase the risk of diseases and obesity in adulthood [39-41]. More studies are needed to clarify the different mechanisms in women and men. However, the life-course approach 
which emphasizes cumulative and social inequality in the development of obesity should not be disregarded $[35,42]$.

As the identified trajectories are but approximations of the true development, and misclassifications cannot be ruled out, it was not possible to judge causality in this design. Childhood adversities were reported retrospectively, and reporting bias is possible. However, due to the nature of the determinants, it is likely that childhood adversities preceded the development of obesity. Further studies are needed to investigate childhood adversities more extensively, because other adversities, such as violence and abuse, have also been identified to be risk factors for later obesity $[9,43]$. Our study lacks information on participants' BMI in childhood, which could explain some of the associations, e.g., being bullied in childhood [44]. Information on participants' BMI was based on self-reports which may have been biased. However, as selfreported BMI, especially among obese people, is often underestimated [45] and false-positive retrospective reports of adversities are probably rare [46], our results (ORs) tend to be underestimates rather than overestimates. A previous HHS study demonstrated that self-reported BMI performed equally to measured BMI when examining the predictive power for sickness absence [47]. Also, a systematic review showed that childhood maltreatment was associated with obesity despite different methods of measurement and assessment [30].

The strength of this study is the large, longitudinal dataset with information on participants' childhood circumstances and body weight in early adulthood. The response rates in all 4 phases were good $(67,83,79$, and $82 \%)$, and the characteristic differences between responders and nonresponders were relatively minor [18]. Participants who were older and in higher occupational positions tended to be more likely to respond in the baseline survey. The HHS cohort participants were agood representation of the target population, i.e., midlife municipal employees in Finland [48]. However, the cohort was not representative of the Finnish general population as it did not include unemployed people, and it has a much higher proportion of women [18]. The considerably smaller number of men in the sample may partly explain our finding of a stronger association between childhood adversities and BMI trajectory among women.

The longitudinal dataset enabled us to use more sophisticated analytic procedures, such as GBTM, rather than several cross-sectional data analyses to identify latent, distinctive longitudinal features. GBTM enabled us to recognize similar subgroups in the development of adulthood BMI, noting that these groups are rather approximations and simplifications of the real BMI trajectories [13]. There are no superior ways to model trajectory data, and the choice of method and selection of the optimal number and shape of trajectories may affect the findings [49]. Although the group sizes remained under 5\% in trajectory group 4, partly resulting in small sample sizes especially among men, 4 distinct trajectories were considered relevant, based on the other model fit statistics and interpretability of the identified trajectory groups. More studies with equal sample sizes for women and men are needed to confirm the gender differences in the associations between childhood adversities and developmental trajectories of adult BMI. Overall, more attention should be paid to the psychosocial health of the most vulnerable children and adolescents to prevent the long-term development of obesity and general health $[8,25]$. In addition, modifying the physical and social environment to support healthy behavior is another way to diminish weight-related health differences between population groups in different socioeconomic situations.

\section{Conclusion}

Our study showed that long-term development of overweight and obesity is common among Finnish municipal employees, and we found 4 ascending BMI trajectories for both women and men. Low parental education for both genders, multiple adversities and repetitive peer group 
bullying in childhood among women, and parental alcohol problems among men increased the odds of developing obesity during adulthood. Understanding the interrelationships between childhood disadvantage, psychosocial health, and health behaviors behind longitudinal weight changes would help to prevent the inequality in the development of obesity and target interventions to the most vulnerable population groups. Further studies are needed to clarify how gender differences modify the effects of childhood adversities on adult BMI trajectories.

\section{Acknowledgement}

We thank the City of Helsinki, its personnel administration, and all participating employees.

\section{Statement of Ethics}

The HHS protocol was approved by the ethics committees of the Department of Public Health, University of Helsinki and the health authorities of the City of Helsinki. Participation in the study was voluntary and relevant ethical codes were strictly followed in all phases of the study. Full confidentiality was guaranteed to all respondents.

\section{Disclosure Statement}

The authors have no conflicts of interest to declare.

\section{Funding Sources}

T.L. was supported by the Academy of Finland (Grants \#287488 and \#319200) and by the Finnish Work Environment Fund (Grant \#117308). O.R. was supported by the Academy of Finland (Grant \#1294514) and the Juho Vainio Foundation.

\section{Author Contributions}

T.L., N.K., and J.S. contributed to the design of the study. T.L. and N.K. assisted with data analysis and participated in critical revision of the manuscript. J.S. performed the data analyses and drafted the first version of the manuscript. E.M. and O.R. were involved in interpreting results and critically reviewed the manuscript. All authors read, critically commented, and approved the final manuscript as submitted.

\section{References}

1 Stevens GA, Singh GM, Lu Y, Danaei G, Lin JK, Finucane MM, et al.; Global Burden of Metabolic Risk Factors of Chronic Diseases Collaborating Group (Body Mass Index). National, regional, and global trends in adult overweight and obesity prevalences. Popul Health Metr. 2012 Nov;10(1):22.

2 Ng M, Fleming T, Robinson M, Thomson B, Graetz N, Margono C, et al. Global, regional and national prevalence of overweight and obesity in children and adults 1980-2013: A systematic analysis. Lancet. 2014 Aug; 384(9945):766-81. 
Salmela et al.: Childhood Disadvantage and Adult BMI Trajectories

3 Chaffee BW, Abrams B, Cohen AK, Rehkopf DH. Socioeconomic disadvantage in childhood as a predictor of excessive gestational weight gain and obesity in midlife adulthood. Emerg Themes Epidemiol. 2015 Mar; 12(1):4.

4 Giskes K, van Lenthe FJ, Turrell G, Kamphuis CB, Brug J, Mackenbach JP. Socioeconomic position at different stages of the life course and its influence on body weight and weight gain in adulthood: a longitudinal study with 13-year follow-up. Obesity (Silver Spring). 2008 Jun;16(6):1377-81.

5 Brisbois TD, Farmer AP, McCargar LJ. Early markers of adult obesity: a review. Obes Rev. 2012 Apr;13(4): 347-67.

6 Riem MM, Karreman A. Childhood Adversity and Adult Health: The Role of Developmental Timing and Associations With Accelerated Aging. Child Maltreat. 2019 Feb;24(1):17-25.

7 Wall MM, Mason SM, Liu J, Olfson M, Neumark-Sztainer D, Blanco C. Childhood psychosocial challenges and risk for obesity in U.S. men and women. Transl Psychiatry. 2019 Jan;9(1):16.

8 Kessler RC, McLaughlin KA, Green JG, Gruber MJ, Sampson NA, Zaslavsky AM, et al. Childhood adversities and adult psychopathology in the WHO World Mental Health Surveys. Br J Psychiatry. 2010 Nov; 197(5):378-85.

9 Thomas C, Hyppönen E, Power C. Obesity and type 2 diabetes risk in midadult life: the role of childhood adversity. Pediatrics. 2008 May;121(5):e1240-9.

10 Cohen S, Janicki-Deverts D, Chen E, Matthews KA. Childhood socioeconomic status and adult health. Ann N Y Acad Sci. 2010 Feb;1186(1):37-55.

11 Ferraro KF, Schafer MH, Wilkinson LR. Childhood Disadvantage and Health Problems in Middle and Later Life: Early Imprints on Physical Health? Am Sociol Rev. 2016 Feb;81(1):107-33.

12 Senese LC, Almeida ND, Fath AK, Smith BT, Loucks EB. Associations between childhood socioeconomic position and adulthood obesity. Epidemiol Rev. 2009;31(1):21-51.

13 Nagin DS, Odgers CL. Group-based trajectory modeling in clinical research. Annu Rev Clin Psychol. 2010;6(1): 109-38.

14 Lee C, Park S. Examining Cumulative Inequality in the Association Between Childhood SES and BMI from Midlife to Old Age. J Gerontol B Psychol Sci Soc Sci. 2019 Jun;gbz081.

15 Clarke P, O'Malley PM, Johnston LD, Schulenberg JE. Social disparities in BMI trajectories across adulthood by gender, race/ethnicity and lifetime socio-economic position: 1986-2004. Int J Epidemiol. 2009 Apr;38(2): 499-509.

16 Sacks RM, Takemoto E, Andrea S, Dieckmann NF, Bauer KW, Boone-Heinonen J. Childhood Maltreatment and BMI Trajectory: The Mediating Role of Depression. Am J Prev Med. 2017 Nov;53(5):625-33.

17 Elsenburg LK, Smidt N, Hoek HW, Liefbroer AC. Body Mass Index Trajectories from Adolescence to Early Young Adulthood: Do Adverse Life Events Play a Role? Obesity (Silver Spring). 2017 Dec;25(12):2142-8.

18 Lahelma E, Aittomäki A, Laaksonen M, Lallukka T, Martikainen P, Piha K, et al. Cohort profile: the Helsinki Health Study. Int J Epidemiol. 2013 Jun;42(3):722-30.

19 Jones BL, Nagin DS. A Note on a Stata Plugin for Estimating Group-based Trajectory Models. Sociol Methods Res. 2013 Nov;42(4):608-13.

20 Liu H, Umberson D. Gender, stress in childhood and adulthood, and trajectories of change in body mass. Soc Sci Med. 2015 Aug;139:61-9.

21 Hiilamo A, Lallukka T, Mänty M, Kouvonen A. Obesity and socioeconomic disadvantage in midlife female public sector employees: a cohort study. BMC Public Health. 2017 Oct;17(1):842.

22 Hiilamo A, Shiri R, Kouvonen A, Mänty M, Butterworth P, Pietiläinen O, et al. Common mental disorders and trajectories of work disability among midlife public sector employees - A 10-year follow-up study. J Affect Disord. 2019 Mar;247:66-72.

23 Poulsen PH, Biering K, Winding TN, Nohr EA, Andersen JH. How does childhood socioeconomic position affect overweight and obesity in adolescence and early adulthood: a longitudinal study. BMC Obes. 2018 Dec;5(1): 34.

24 Howe LD, Tilling K, Galobardes B, Smith GD, Ness AR, Lawlor DA. Socioeconomic disparities in trajectories of adiposity across childhood. Int J Pediatr Obes. 2011 Jun;6(2-2):e144-53.

25 Halonen JI, Stenholm S, Pentti J, Kawachi I, Subramanian SV, Kivimäki M, et al. Childhood Psychosocial Adversity and Adult Neighborhood Disadvantage as Predictors of Cardiovascular Disease: A Cohort Study. Circulation. 2015 Aug;132(5):371-9.

26 Felitti VJ, Anda RF, Nordenberg D, Williamson DF, Spitz AM, Edwards V, et al. Relationship of childhood abuse and household dysfunction to many of the leading causes of death in adults. The Adverse Childhood Experiences (ACE) Study. Am J Prev Med. 1998 May;14(4):245-58.

27 Wang M, Yi Y, Roebothan B, Colbourne J, Maddalena V, Wang PP, et al. Body Mass Index Trajectories among Middle-Aged and Elderly Canadians and Associated Health Outcomes. J Environ Public Health. 2016;2016: 7014857.

28 Botoseneanu A, Liang J. Social stratification of body weight trajectory in middle-age and older americans: results from a 14-year longitudinal study. J Aging Health. 2011 Apr;23(3):454-80.

29 Kuchibhatla MN, Fillenbaum GG, Kraus WE, Cohen HJ, Blazer DG. Trajectory Classes of Body Mass Index in a Representative Elderly Community Sample. The Journals of Gerontology: Series A. 2013 Jun;68(6):699-704. https://doi.org/10.1093/gerona/gls215.

30 Danese A, Tan M. Childhood maltreatment and obesity: systematic review and meta-analysis. Mol Psychiatry. 2014 May;19(5):544-54. 
Salmela et al.: Childhood Disadvantage and Adult BMI Trajectories

31 Song M, Zheng Y, Qi L, Hu FB, Chan AT, Giovannucci EL. Longitudinal Analysis of Genetic Susceptibility and BMI Throughout Adult Life. Diabetes. 2018 Feb;67(2):248-55.

32 Puhl RM, Luedicke J. Weight-based victimization among adolescents in the school setting: emotional reactions and coping behaviors. J Youth Adolesc. 2012 Jan;41(1):27-40.

33 Benson R, von Hippel PT, Lynch JL. Does more education cause lower BMI, or do lower-BMI individuals become more educated? Evidence from the National Longitudinal Survey of Youth 1979. Soc Sci Med. 2018 Aug;211: $370-7$.

34 Bakalar JL, Barmine M, Druskin L, Olsen CH, Quinlan J, Sbrocco T, et al. Childhood adverse life events, disordered eating, and body mass index in US Military service members. Int J Eat Disord. 2018 May;51(5):465-9.

35 Ben-Shlomo Y, Kuh D. A life course approach to chronic disease epidemiology: conceptual models, empirical challenges and interdisciplinary perspectives. Int J Epidemiol. 2002 Apr;31(2):285-93.

36 Evans GW, Fuller-Rowell TE, Doan SN. Childhood cumulative risk and obesity: the mediating role of self-regulatory ability. Pediatrics. 2012 Jan;129(1):e68-73.

37 Bann D, Cooper R, Wills AK, Adams J, Kuh D; NSHD scientific and data collection team. Socioeconomic position across life and body composition in early old age: findings from a British birth cohort study. J Epidemiol Community Health. 2014 Jun;68(6):516-23.

38 Gebreab SZ, Vandeleur CL, Rudaz D, Strippoli MF, Gholam-Rezaee M, Castelao E, et al. Psychosocial Stress Over the Lifespan, Psychological Factors, and Cardiometabolic Risk in the Community. Psychosom Med. 2018 Sep; 80(7):628-39.

39 Bosch NM, Riese H, Reijneveld SA, Bakker MP, Verhulst FC, Ormel J, et al. Timing matters: long term effects of adversities from prenatal period up to adolescence on adolescents' cortisol stress response. The TRAILS study. Psychoneuroendocrinology. 2012 Sep;37(9):1439-47.

40 Danese A, McEwen BS. Adverse childhood experiences, allostasis, allostatic load, and age-related disease. Physiol Behav. 2012 Apr;106(1):29-39.

41 Pinto Pereira SM, Stein Merkin S, Seeman T, Power C. Understanding associations of early-life adversities with mid-life inflammatory profiles: evidence from the UK and USA. Brain Behav Immun. 2019 May; 78:143-52.

42 Ferraro KF, Shippee TP. Aging and cumulative inequality: how does inequality get under the skin? Gerontologist. 2009 Jun; 49(3):333-43.

43 Midei AJ, Matthews KA. Interpersonal violence in childhood as a risk factor for obesity: a systematic review of the literature and proposed pathways. Obes Rev. 2011 May;12(5):e159-72.

44 Janssen I, Craig WM, Boyce WF, Pickett W. Associations between overweight and obesity with bullying behaviors in school-aged children. Pediatrics. 2004 May;113(5):1187-94.

45 Connor Gorber S, Tremblay M, Moher D, Gorber B. A comparison of direct vs. self-report measures for assessing height, weight and body mass index: a systematic review. Obes Rev. 2007 Jul;8(4):307-26.

46 Hardt J, Rutter M. Validity of adult retrospective reports of adverse childhood experiences: review of the evidence. J Child Psychol Psychiatry. 2004 Feb;45(2):260-73.

47 Korpela K, Roos E, Lallukka T, Rahkonen O, Lahelma E, Laaksonen M. Different measures of body weight as predictors of sickness absence. Scand J Public Health. 2013 Feb;41(1):25-31.

48 Laaksonen M, Aittomäki A, Lallukka T, Rahkonen O, Saastamoinen P, Silventoinen K, et al. Register-based study among employees showed small nonparticipation bias in health surveys and check-ups. J Clin Epidemiol. 2008 Sep;61(9):900-6.

49 Warren JR, Luo L, Halpern-Manners A, Raymo JM, Palloni A. Do Different Methods for Modeling Age-Graded Trajectories Yield Consistent and Valid Results? AJS. 2015 May;120(6):1809-56. 